\title{
Bioanalogues of juvenile hormones and intestines mycoflora of some insects
}

\author{
ANDRZEJ NESPIAK $\mid *$, ANDRZEJ ZABZA **, MARIA KUSIAK ** \\ * Medical Academy, Department of Biology and Farmaceutical Botany, Kocha- \\ nowskiego 10, 51-601 Wroclaw; ** Institut of Organic and Physical Chemistry, \\ Technical University, Łukasiewicza 2, 50-371 Wrocław
}

Nespiak A., Z a bża A., Kusiak M.: Bioanalogues of juvenile hormones and intestines mycoflora of some insects, Acta Mycol. 18(1): 61-69, 1982.

The subject of this paper is the influence of $\mathrm{JH}$ bioanalogues on the mycoflora of intestines of three species of inscets: Dysdereus cingulatus, Pyrrhocoris apterus and Tenebrio molitor. The results are presented in tables.

Hormones undoubtedly belong to the most important biologicalactive compounds exhibiting high selectivity of action. Their action, controlling almost all reactions proceeding in a living organism, determines the corectness of its development. On the other hand, factors disturbing the hormonal administration cause stable irreversible changes.

A new direction of research concerning the insect juvenile hormones has developed during recent years creating possibilities of their application as "3rd generation insecticides" (Williams 1956; 1967). Synthetic bioanalogs of juvenile hormones exhibit an activity analogous to that of natural compounds produced in an insect body by so-called corpora allata. During the postembryonal growth of insects, changes in the endogeneous level of natural $\mathrm{JH}$, regulating essentially the efficient course of metamorphosis, are observed (S l a m a 1971; S e h n a l 1971). The introduction of a synthetic bioanalog of $\mathrm{JH}$ on the body surface or to the intestines during the suitable development stage of an insect results in morphogenetic changes manifesting themselves in the formation of intermediate forms, so-called adultoids, and of additional larval stages, so-called superlarvae, incapable of further development and reproduction (S 1 a $\mathrm{m}$ a 1974).

Juvenile hormones and their bioanalogs are characterized by the high 
selectivity of action, thus man has gained a new weapon in the fight against econemically harmful species of insects - the factor acting on exactly one definite species and apparently not disturbing the balance of nature.

The first compound from the juvenoids group which in obtained 1975 the permission of the Agency of Environment Protection of USA for sale the was isopropyl ester of ZE, 4E-11-methoxy-3,7,11-trimethyldodeca-2,4-dienic acid called Metopren (D jerassi 1974-75). It was applied in preparations of the Altosid type for exterminating larvae ot mosquitoes and other Diptera, including the housefly.

There are many methods for determinating the biological activity of $\mathrm{JH}$ bioanalogs. They are similar to methods used in investigations of hormonal effects in living cells. Thus, the method of estimation of $\mathrm{ED}_{50}$ (éffective dose $50^{\%} \%$ ), $\mathrm{ID}_{50}$ (inhibition dose $50^{\circ} \%$ ), ID $\mathrm{ID}_{50}$-Ovic. (inhibition dose $50^{\circ} \%$ Ovicidal) and many others are applied. The action of juvenoids is estimated in all cases on the basis of external morphogenetic effects on the insect body caused by them. The field experiments of application of new compounds of the juvenoid type have shown that insects from the natural environment react to these compounds in a different manner than insects raised in a laboratory for years. Contrary to the standard laboratory conditions, the population of insects whose growth proceeds in the natural environment is more or less heterogeneous. Various conditions in which the populations of definite species of insects grow in the natural environment can essentially influence the effectiveness of the action of juvenoids. Thus, the relationships between laboratory and field effectiveness of these compounds action of various stabilitie should be considered (S l a m a 1974).

There are hypotheses that insects owe the resistance to the action of juvenoids to symbiotic microorganisms living inside or on the surface of their bodies (Wigglesworth 1974, Sla ma et al. 1971). Their metabolic products, gathering in the insect body, can affect the metabolism of its own cells which can next control the reactions of the organism on the external impulse, the action of bioanalogs of juvenile hormones. This thesis should, of course, be confirmed by experiments which are the subject of this work. They were limited to the study of mycoflora of three insect species tested for the action of juvenoids. The work presents a preliminary analysis of flora of fungi existing in the intestines of these insects. The studies should give answers to a series of questions: has this flora any definite character, is it specific for each tested species, and does it change under action of the definite IH bioanalogs? The known phenomena of the stable biological relationships between insects and fungi allow us to consider the problem in such 
a way. For example, the fungal species from the genus Termitomyces lives exclusively inside the heaps of termites ( $\mathrm{Heim}$ 1942). The mycelium of a representative of the Septobasidiaceae family forms the specific environment for some insect species from the family Coccideae (Couch 1938). Fungi from the order Laboulbeniales, living on the surface of wing-sheaths, are also closely bound with the life of insects. These fungi are, in the opinion of many specialists (Gä umann 1964 and others), ectoparasites decomposing chitin and they exhibit more rarely a tendency to the parasitism of internal organs of insects. Gams (1971) mentioned a series of saprophytic species, living on media rich in chitin, in the monography of fungi sporulating according to the Cephalosporium type. They are fungi in which the boundary between the saprophytic and parasitic phase is labile. They exist on the body surfaces of arthropods and some of them become typical parasites. Then their mycelium overgrows the tissues of larvae, pupae, or imago stage. The species from the genus Verticillium and Aphanocladium are most often mentioned in the literature. These fungi especially prefer the chitin insect bodies for their development or they live in the intestines of insects as saprophytic mycoflora.

\section{MATFRIALS AND METHODS}

The studies were carried out on three insect species: Dysdercus cingulatus L. and Pyrrhocoris apterus L. from the family Pyrrinocoridene, and Tenebrio molitor L. from the family Tenebrionideae. The two former species were raised in glass jars at $\pm 24^{\circ} \mathrm{C}$ and at a relative humidity of $70-75 \%$. D. cingulatus were fed with cotton seeds, $P$. apterus - with Tilia seeds. The cultivation of Tenebrio molitor was carried out at $\pm 27^{\circ} \mathrm{C}$ and at $70-80 \%$ of relative humidity. Their diet contained bran, yeasts, flour, and flaked oats.

The normally developed insects in the imago stage, the fifth larval stage, pupae (for T, molitor), and adultoids, resulted from the topical application of $1 \mu \mathrm{l}$ of acetonic solution of juvenoid on the cuticle of a freshly moulted larva or pupa $(0-20 \mathrm{hrs}$ after moulting for $D$. cingulatus and $P$, apterus, 1-24 hrs - for T. molitor), which were used for isolation. Fungi were isolated from individual insects after their superficial desinfection (washing with a $40^{\%} \%$ alcohol solution) under sterile conditions. Skeletonized fragments of the intestines of an insect were laid out in Petri-dishes with the agar medium. The appearing colonies of fungi were put on the agar slants and then purified by the method of dilution into one-spore cultures. The growth and development of the fungal colonies were carried out at about $26-28^{\circ} \mathrm{C}$. The pure cultures 


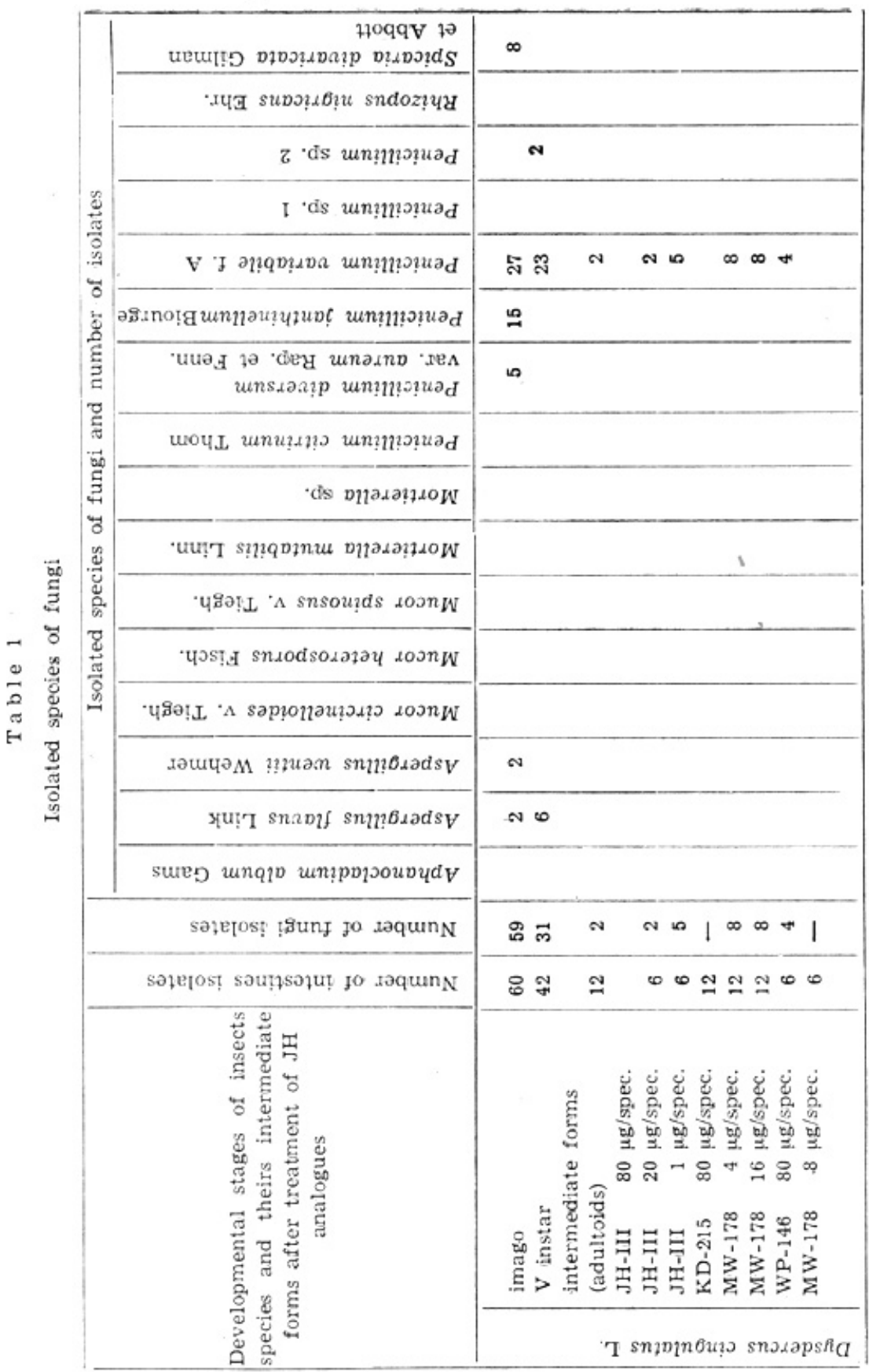




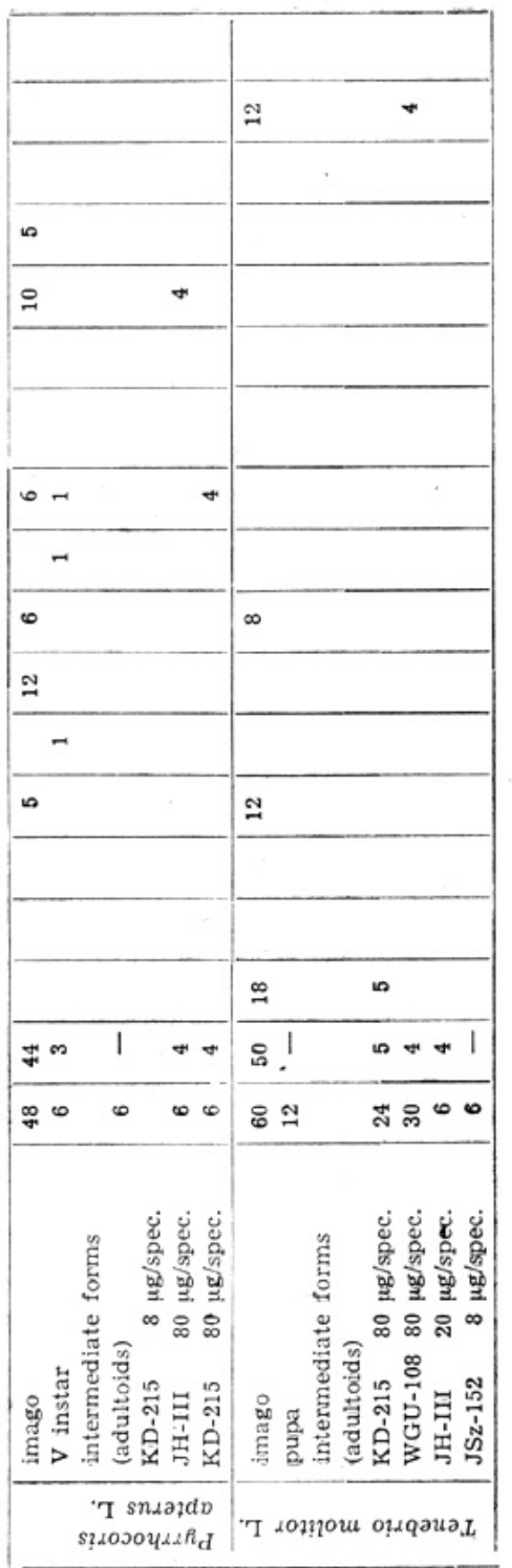




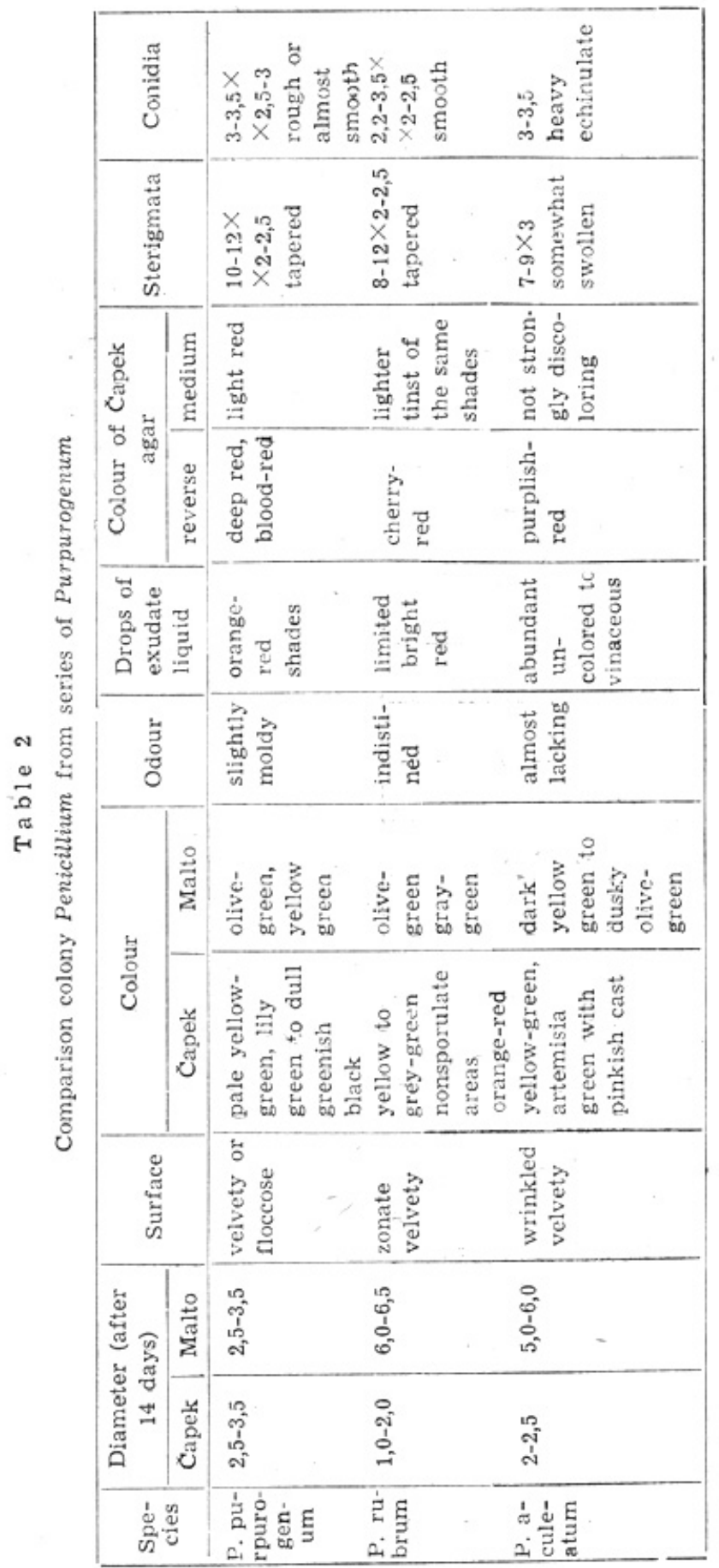




\begin{tabular}{|c|c|c|}
\hline 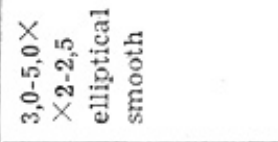 & & 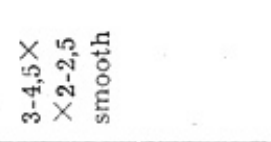 \\
\hline 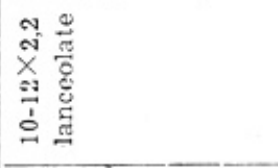 & 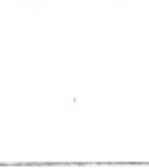 & 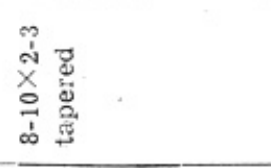 \\
\hline 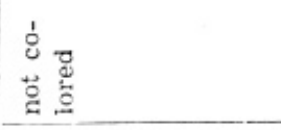 & $\therefore$ & 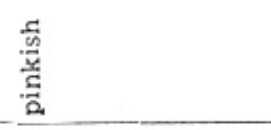 \\
\hline 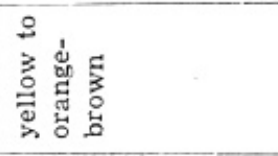 & & 章芯 \\
\hline 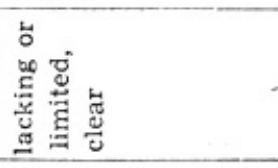 & - & 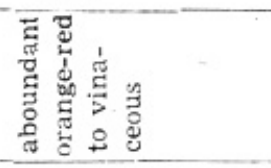 \\
\hline 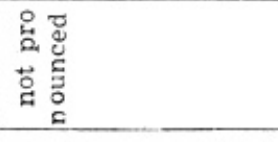 & & 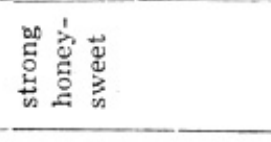 \\
\hline 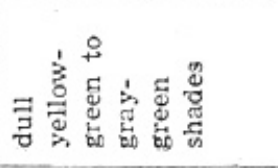 & & 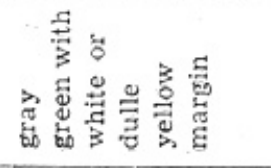 \\
\hline 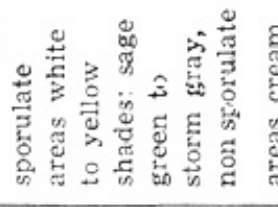 & 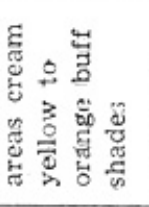 & 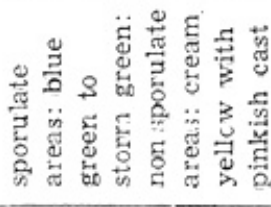 \\
\hline 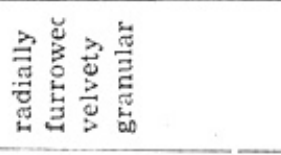 & & 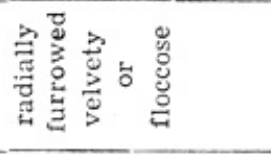 \\
\hline 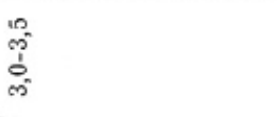 & & $\begin{array}{l}\text { Oे } \\
\text { ì } \\
\text { ì }\end{array}$ \\
\hline 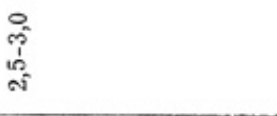 & & 品 \\
\hline 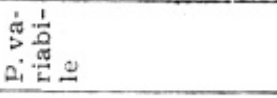 & & 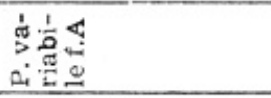 \\
\hline
\end{tabular}


were included in definite genus or species using corresponding keys or treatises of the monography type. The following compounds, designated with conventional symbols in Fig. 1, were used as the bioanalogs of juvenile hormones.

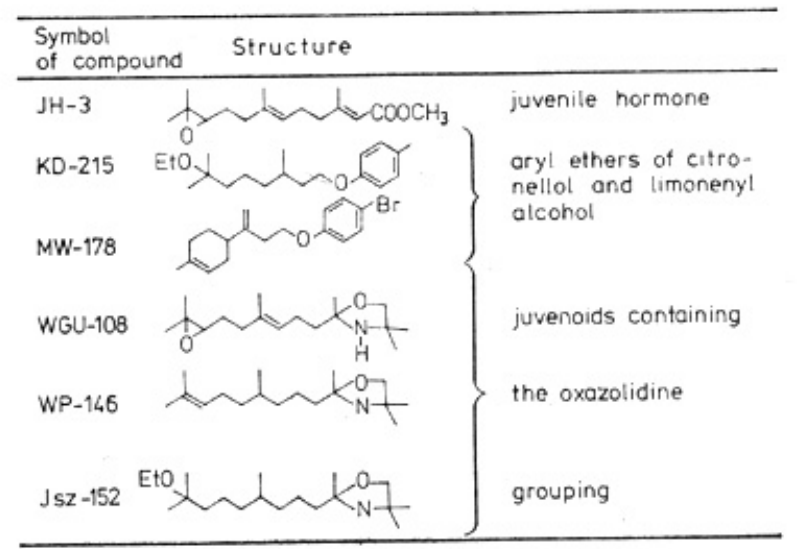

Fig. 1

Media used for the cultivation of fungi

Agar malto $-25 \mathrm{~g}$ of maltose extract, $1000 \mathrm{ml}$ of distille water, $15 \mathrm{~g}$ of agar.

Capek's agar $-1000 \mathrm{ml}$ of distilled water, $3.0 \mathrm{~g}$ of $\mathrm{NaNO}_{3} ; 1.0 \mathrm{~g}$ of $\mathrm{K}_{2} \mathrm{HPO}_{4}$; $0.5 \mathrm{~g}$ of $\mathrm{MgSO}_{4} \cdot 7 \mathrm{H}_{2} \mathrm{O} ; 0.5 \mathrm{~g}$ of $\mathrm{KCl} ; 0.01 \mathrm{~g}$ of $\mathrm{FeSO}_{4} \cdot 7 \mathrm{H}_{2} \mathrm{O}$; $30.0 \mathrm{~g}$ of saccharose; $20.0 \mathrm{~g}$ of agar.

\section{RESULTS OF EXPERIMENTS}

396 isolations of fragments of intestines of three insect species under investigation were carried out (186 for Dysdercus cingulatus, 72 for Pyrrhocoris apterus, and 138 for Tenebrio molitor); 243 incula, belonging to 16 species of fungi, were received from them (Table 1). The species from the genus Penicillium occurred most of ten among them (6 species). The species designated provisionally as Penicillium variabile f. A was isolated predominantly. Comparison of this form with other species of the series Purpurogenum is presented in Table 2. The species from the family Mucoraceae (Mucor circinelloides, M. spinosus, Rhizopus nigricans) and Aphanocladium album producing spores according to the Cephalosporium type were isolated in small numbers.

The results obtained allow some conjectures to be made:

1. Certain specificity of fungal species living inside intestines of 
definite insects can be observed. Among seven species isolated from intestines of Dysdercus cingulatus, only two are common to those living in Pyrrhocoris apterus, not one, however, occurred in the isolates from Tenebrio molitor.

2. A distinct difference occurs in the number of fungal species isolated from the imago and adultoid stage. In the last case the fungal flora is markedly poorer or even nonexistent. In the case of Dysdercus cingulatus, only one- species (Penicillinum variabile f. A) was isolated from adultoids. From the adultoids of Pyrrhocoris apart from this species $P$. citrinum was obtained additionally. Adultoids of Tenebrio had two fungi (Rhizopus niger and Aphanocladium album) in intestines.

3. While the intestines of two species, Pyrrhocoris apterus and Dysdercus cingulatus belonging to the same family Pyrrhocorideae, were a suitable environment for the development of the ubiquitous species Penicillium, these fungi were not found in Tenebrio molitor. The greatest number of isolates from this species belonged to Aphanocladium album, the fungus mentioned in the literature ( $\mathrm{Gams}$ ) as a chitinophilous species.

4. The imagoes and larvae of Pyrrhocoris apterus had the most differentiated composition of fungi (9 species), the imagoes of $T$ 2nebrio molitor - the poorest one (4 species).

\section{REFERENCES}

Couch J. N., 1938, The genus Septobasidium. Chapel Hill N. C.

Djerassi C., 1974-75, First Products, Marketing and Manufacturing Plants.

Zoecon Corpor. Ann. Rep. for the Year Ended December.

Gams W., 1971, Cephalosporiumartige Schimmelpilze, G. Fischer, Stuttgart.

Gä u m a n n E., 1969, Die Pilze. Birkhäuser Verl. Basel.

Heim R., 1942, Nouvelles études descriptives sur les Agarics termitophiles

d'Afrique tropicale. Arch. Mus. Nat.

Sehnal F., 1971, Endocrines of Arthropods. Chem, Zool. Acad. Press.

Sla ma K., 1971, Insect juvenile hormone analogues. Ann. Rev. Biochem.

\$ $1 \mathrm{am}$ a K., Romanuk M., Sorm F., 1974, Insect Hormones and Bionalogues.

Springer-Verl, Vien-New York.

Wiggleswbrth V. B,, 1974, The Principles of Insect. Physiology, Chapman and Hall, London.

Willi a m s C. M., 1956, The juvenile hormone of Insect. Nature.

Williams C. M., 1967, Third Generation Pesticides. Sci. American. 